\title{
Steps forward towards developing preschoolers ' digital literacy. An experience report
}

\author{
Anamaria Moldovan \\ Bee Kindergarten, 27, \\ Gr.Alexandrescu, \\ Cluj-Napoca, Romania \\ anabeekindergarten@gmail.com
}

\author{
Adriana-Mihaela Guran \\ Babes-Bolyai University \\ 1, M.Kogalniceanu, \\ Cluj-Napoca, Romania \\ adrianalcs.ubbcluj.ro
}

\author{
Grigoreta-Sofia Cojocar \\ Babes-Bolyai University \\ 1, M.Kogalniceanu, \\ Cluj-Napoca, Romania \\ grigo@cs.ubbcluj.ro
}

DOI: $10.37789 /$ rochi.2020.1.1.2

\begin{abstract}
Early childhood education (ECE) encompasses, at its most basic level, all forms of education, both formal and informal, provided to young children up to approximately 8 years of age. Some of the benefits include a diminished risk of social-emotional mental health problems and increased self-sufficiency as children mature and enter adulthood. It is during this period that children go through the most rapid phase of growth and development. Their brains develop faster than at any other point in their lives, so these years are critical. The foundations for their social skills, self-esteem, perception of the world and moral outlook are established during these years, as well as the development of cognitive skills. Lately, digital literacy and its practices are added as a need for future personal and professional development of children and developing digital competence already at kindergarten level can also help to raise awareness on safety issues and build critical thinking among them regarding content and devices that they use. This paper describes a new approach in supporting the development of digital literacy skills of preschoolers aged 5 to 6 in the context of Human-Computer Interaction (HCI) students volunteering for ICT activities in kindergarten along with building edutainment applications. There is also a report of key digital competences established by the kindergarten teachers involved, and monitored for formation during the activities.
\end{abstract}

\section{Keywords}

Education; Digital literacy; Interaction; Human; Preschoolers; Key Competences; ICT activities

\section{ACM Classification Keywords}

H.5.m. Information interfaces and presentation (e.g., HCI): Miscellaneous

\section{INTRODUCTION}

The Romanian educational system has made significant progress in recent decades, consolidating its institutions and improving students` learning outcomes. However, although it gives some students a chance to excel, many others do not master basic skills and almost one-fifth drop out of school before graduating from high school. Creating an educational system where all students have access to quality education and are supported to give their best will improve further performance and the process of learning, thus supporting individual well-being and growth at the national level.

Romania is currently implementing an ambitious curriculum, focused on student-guided learning and the development of key competencies. In this way, it has the opportunity to achieve a deeper transformation in terms of what is appreciated and taught in the classroom throughout the country. Strengthening the evaluation and examination system in the sense of establishing high expectations for all students but also training practices that contribute to the development of students, teachers and schools will play an essential role in achieving this transformation and creating a more equitable educational system in which all students have access to quality education [4,19].

The basis of the ability to learn throughout life is formed in the early years of childhood. Learning is a gradual process, and building strong premises in early childhood is a prerequisite for the development of skills and educational success at higher levels, being equally essential for the health and well-being of children. In this context, the goals of early education aim at a series of aspects, which frame the premises of the key competencies formed, developed and diversified, on the path of further schooling. Each European country established the level of ECE regarding the age of children and organized the educational system and the curricula according to that.

The curriculum for early education capitalizes on the curricular paradigm centered on competences and bases the educational approaches on the child and on his/ her learning activity as a process, respectively on the acquisition of behaviors that will ensure the premises for the development of key competences later. Taking into account the peculiarities of the child's development up to 6 years (the age limit for ECE in Romania), it is not appropriate to use the concept of competence, understood as an integrated set of knowledge, skills and attitudes [8,9,18]. Competence 
involves the existence of cognitive patterns and patterns of behavior, so a higher level of development than that reached by typical children in the 0-3 years and even 3-6 years. The Recommendation of the European Parliament and of the Council, 23 April 2008, regarding the European Framework Qualifications for lifelong learning [21] describes competence from the perspective of responsibility and autonomy as a proven ability to use personal, social and/or methodological knowledge, skills and abilities in work or study situations and for professional and personal development.

The option to use key competences as benchmarks in establishing the training profile for pre-university education was an important decision of educational policy promoted by the National Education Law no. 1/2011. Early education is established to be the heart in developing these competencies, starting from the model of structuring the development levels of eight key competence domains, in relation to the pre-university education levels. These are: communication in the native language; communication in foreign languages; mathematical skills and basic skills in science and technology; digital competence; to learn how to learn; social and civic skills; spirit of initiative and entrepreneurship; awareness and cultural expression $[4,19,21]$.

Communication skills in foreign languages and digital competences are not directly covered by the early education curriculum, but it is recommended that, as far as available resources allow, they should be addressed through the carrying out activities [4].

In the next sections, we present the educational context, the strategy and the observations listed at the end of ICT activities organized with the help of volunteering HCI students for preschoolers aged 5 to 6 in terms of behaviors and attitudes towards technology (computer, laptop).

\section{EDUTAINMENT APPLICATIONS}

The role of games in learning has been studied for years ago, and it has been proven that no matter the age, mixing fun with learning is appropriate and brings valuable results. This is because the elements of games determine immersion, engagement and motivation for the learners. Moreover, when the final users of an application with an educational intended role are preschoolers, the presence of a narration or game elements become a must. Edutainment applications combine learning with playing. Designing edutainment applications is challenging because it needs to envelop the learning content and tasks in the scenario of a game $[10,20]$. Designing edutainment for preschoolers is even more challenging due to the constraints introduced by their development. The previous experience in designing edutainment applications [12, 14] and computer aided assessment applications brought the determination to address in a new manner the support provided for digital skills development of preschoolers.

To support the development of digital skills of preschoolers the intervention on multiple aspects is needed:

- children should be exposed to interactive applications that are appropriate for their age in terms of content, tasks and interaction actions that are required. Because there are many differences between preschoolers in the small group (3-4 years old), middle group (4-5 years old) and large group (5-6 years old) specific applications should be designed and developed for each age range;

- children should be gently introduced to the ICT world, by presenting them the fundamentals of computers, and interaction with them;

- monitoring the results of using the edutainment applications is necessary. The results should be assessed in terms of knowledge acquired by the children and development/improvement of digital skills.

In the following it is described the approach that has been used to cover all the previously mentioned aspects.

\section{Designing developmentally appropriate edutainment} applications

The development of edutainment applications for preschoolers is a challenging task from the following perspectives:

- The final users are very small children that cannot read or write and have reduced communication skills;

- Mixing education and fun needs creativity and good design and programming skills;

- Differences between the preschoolers' age groups are considerable, so preschoolers cannot be seen as a homogenous group;

- There is a lack of design guidelines that address children of 3 to 6 years; most of the recommendations are considering children between 0 and 12 years, with no differentiation;

- The use of existing user centered design methods needs adaptation due to the age of the final users;

- The assessment methods of the final products should refer to usability from the children' perspective, acceptance from kindergarten teachers and efficiency comparatively with the classic teaching method. 
We have previous experience in developing edutainment applications using an adapted User Centered Design (UCD) approach $[12,13,14,15]$. The adaptation refers to the involvement of children during the design process. In the previous work, kindergarten teachers have been proposed as surrogate of the children during the design alternative step, due to the abstract nature of the design sketches. Another approach, more expensive, is to merge the design alternative and prototyping step, such that children could effectively participate with feedback on the proposed solution. During the user centered design process both preschool children and educational experts (kindergarten teachers) have been involved due to the educational goal of the developed applications, while during the assessment step also the preschooler's parents were involved to create an overall image on children' attitude toward their interaction experience.

Assessing the developed education applications with the final users needs adaptation, because the methods applied with adult users cannot be applied similarly with such small children. Observation was considered as a valuable assessment method, together with smileyometers and peer tutoring. Because children are usually willing to please the adults, the use of interviews to gather their subjective opinion on the applications is not relevant. In [11] we have proposed a method to automatically identify children' emotion during the interaction. The main focus was on identifying the presence of negative emotions and the interaction context where they have occurred, to guide our future redesign decisions.

\section{Introducing ICT concepts to preschoolers}

After having the experience of designing and developing edutainment applications for preschoolers the conclusion that it would be helpful to prepare children for their interaction tasks was drawn. Although the current generation of preschoolers are digital natives, they have reduced experience with personal computers and/or laptops. The idea that children should be introduced to these devices, to know basic things about their components and roles along with using the applications became a must do. In this perspective, the curriculum for an optional ICT class called "A computer to learn!' $[2,3,5,6,16,17]$ was conceived with the help of kindergarten teachers involved. The curriculum approaches the following subjects: understanding of devices we use, the components of a personal computer, input and output devices, tasks from children ' usual activities that can be automated using the computers (drawing, typing letters and digits, and coloring) $[3,20,22]$. Similar to the design of edutainment applications tasks, all the activities were conceived as games. Support in teaching the optional course has been received from the third year students from the Faculty of
Mathematics and Computer Science attending the Human-Computer Interaction optional course. All of the students were involved at the same time in the design and development of edutainment applications. Teams of 3 to 5 students have interacted with groups of 20-25 preschoolers in 40 minutes sessions/week for six weeks. During the ICT optional classes children have been introduced to theoretical information on the basic concepts presented before (see Figure 1.) followed by a practical part where they have had the chance to practice fundamental interaction tasks (using the mouse and the keyboard to perform various tasks as Figure 2. shows).

Each team of students organized an activity using intuitive materials as drawings, pictures and their own devices. They also organized games such as a role-play with four children involved-one was the child, one the mouse, one the hard, one the file on the desktop; When the child pressed the left side of the mouse giving an order, the hard processed and the file opened. Another played game organized children in four groups and four children at the same time were supposed to move according to the arrow shown by one of the students that held the activity. The movements stopped when the first child in the row reached a piece of paper where it was written ENTER.

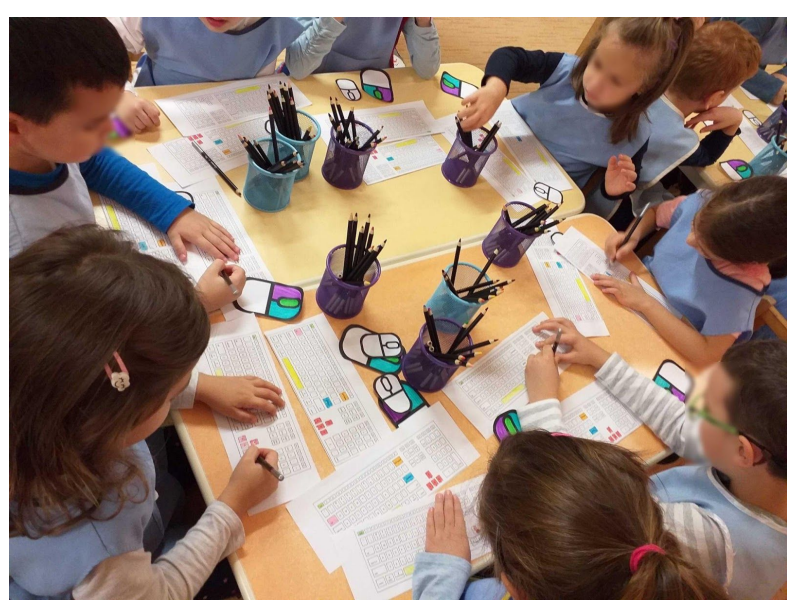

Figure 1. Activity example for introducing the keyboard and the mouse

All the actions imitated during games were then practised on real devices: computer and laptops. Many pictures were taken for parents to see a part of the activities as they all agreed to their children participation and the use of them for academic purposes as articles or presentations. 


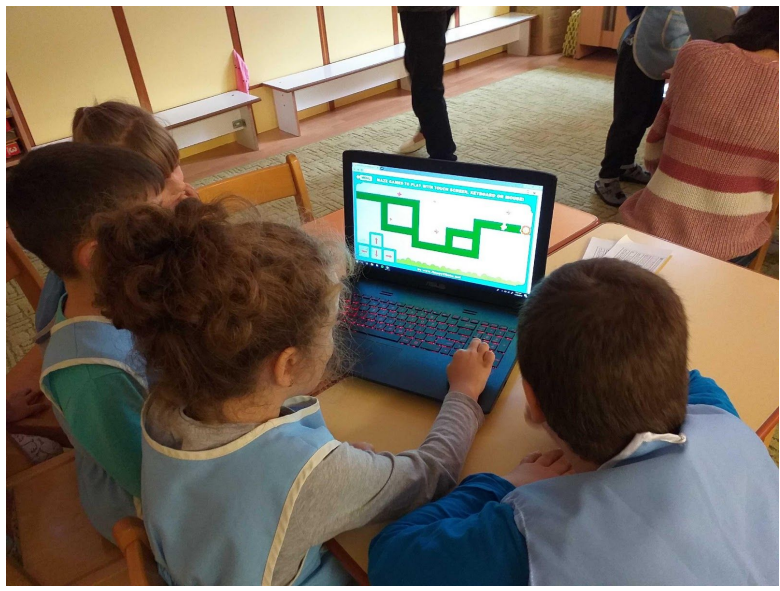

Figure 2. Practical activity

\section{Following the nurturing of digital skills}

Focusing the educational process on the child, a fully accepted principle of contemporary education, implies essentially the permanent concern of teachers for the knowledge of the child as individuality and adaptation of educational programs to the individual profile. From this perspective, the consideration of the child as a whole, as a structured set of defining features, needs, inclinations, potential in a close determination and mutual relations is an essential condition for the formation, through specific means of education, of integral and harmonious personalities $[4,5,18]$.

This implies, first of all, the recognition of the child as an individuality, a personality in formation, whose areas of manifestation - physical, spiritual, emotional, cognitive, social -, influence each other and develop simultaneously, each of these being equally important and having to be the object of early education. Consequently, the edutainment applications offered during the education period from 1 to 6 years must identify and use curriculum sequences that address not only the cognitive area of the personality, but also the affective, social and motor ones, so that the development in a certain side can support and stimulate the evolution of the other sides and the personality as a whole.

The unique character of the child's personality is also given by the specifics of the individual needs of knowledge and training of the child which are considered more and more often, in contemporary pedagogy, the starting point of the educational intervention $[4,5,18]$.

As ECE gained importance and all the recommendations for future socio-economic development of EU countries began from this point, the educational policies changed and adapted their curriculas in terms of key competencies to be followed for formation during the entire school period and further. Preschool stage, kindergarten time is now considered the heart of the whole educational system so the curriculum has been adapted to cover the newly promoted tendencies.

Due to peculiarities of the child's development up to 6 years, it is not appropriate to use the concept of competence, understood as an integrated set of knowledge, skills and attitudes, but behaviors and attitudes separately can be established and purchased in achieving.

Also, digital competences are not directly covered by the early education curriculum in Romania, but it is recommended that, as far as available resources allow, they should be addressed through the carrying out activities. The context of designing appropriate edutainment applications and of introducing ICT concepts to preschoolers proved to be a resourceful one in observing the nurturing of preschoolers`'digital skills.

Behaviour covers knowledge and skills used by the individual in certain specific situations. If it is noticeable, it can be evaluated through the quality of the performing actions and the quality of the results $[5,8,9]$.

As a mandatory task for the approval of the ICT class, there were formulated actions in terms of behaviours, complying with preschoolers ' needs and features $[4,5,18]$ along with content and goals, all these by the kindergarten teachers involved during activities. Behaviours stated into the curricula were considered a prediction of what children should be able to perform at the end of the activities and gave the teacher the possibility to observe and list their occurrence. Thus, twenty kindergarten children were monitored during the six weeks of ICT activities, through observation. Interviews have been organized and the key-word in the frequency of occurring behaviors was considered: constantly - the child does all the actions alone or the child does the actions with help-only helped. The choice of the word was not random but correlated to the specific of the behaviors which, in patterns, develop into competence $[5,8,9]$.

\section{FINDINGS}

Although there is not yet the case of extracting data from an experiment and much work stands ahead, it can surely be stated that the goals established for the ICT class [2] were achieved. Behaviors mentioned below, and their observed frequency could be a starting point for further actions and improvements, as all actors involved in the process of education, teachers, children, parents, community, proved to be more than supportive.

\section{Frequency}




\begin{tabular}{|c|c|c|}
\hline $\begin{array}{l}\text { Observed/monitored } \\
\text { behaviors }\end{array}$ & $\begin{array}{l}\text { Constantly- } \\
\text { alone/Total } \\
\text { number of } \\
\text { children }\end{array}$ & $\begin{array}{l}\text { Constantly- } \\
\text { only } \\
\text { helped/Tota } \\
1 \text { number of } \\
\text { children }\end{array}$ \\
\hline $\begin{array}{l}\text { Recognizes and differentiate } \\
\text { the components of a computer: } \\
\text { screen, keyboard, mouse }\end{array}$ & $20 / 20$ & $0 / 20$ \\
\hline $\begin{array}{l}\text { Interacts: turn on/turn off the } \\
\text { computer, click execution, } \\
\text { double-click, right click, drag \& } \\
\text { drop, mouse selection, usage of } \\
\text { ENTER, SPACEBAR, ESC } \\
\text { buttons, open an application, } \\
\text { close an application }\end{array}$ & $\begin{array}{l}8 / 20 \\
\text { but not all } \\
\text { the } \\
\text { behaviors at } \\
\text { the same } \\
\text { time }\end{array}$ & $12 / 20$ \\
\hline $\begin{array}{l}\text { Recognizes elements of } \\
\text { interaction in WIMP interfaces }\end{array}$ & $4 / 20$ & $16 / 20$ \\
\hline $\begin{array}{l}\text { Recognizes interaction graphics } \\
\text { and their meaning (menu, } \\
\text { button, radio button, checkbox, } \\
\text { text field) }\end{array}$ & $5 / 20$ & $15 / 20$ \\
\hline $\begin{array}{l}\text { Uses basic commands in } \\
\text { Microsoft Paint-choosing } \\
\text { colours, cutting and copying, } \\
\text { choosing graphics }\end{array}$ & $4 / 20$ & $16 / 20$ \\
\hline $\begin{array}{l}\text { Responds to a command, } \\
\text { performing the interaction }\end{array}$ & $16 / 20$ & $4 / 20$ \\
\hline $\begin{array}{l}\text { Expresses the desire to perform } \\
\text { a certain interaction }\end{array}$ & $20 / 20$ & $0 / 20$ \\
\hline $\begin{array}{l}\text { Demonstrates perseverance in } \\
\text { performing a task }\end{array}$ & $13 / 20$ & $7 / 20$ \\
\hline $\begin{array}{l}\text { Verbalizes the performed } \\
\text { interaction }\end{array}$ & $0 / 20$ & $20 / 20$ \\
\hline
\end{tabular}

Table 1: Listed behaviours and their occurrence during ICT activities

During the activities they performed in the kindergarten, whether it was an ICT one or the edutainment application assessment, students have remarked and underlined the joy, enthusiasm and willingness of children to interact with them and their products, to explore and to replay the games, challenging and motivating them.

On the other side, children gained new playing experience and a proper attitude towards technology translated into: "computers are built and organized by people and we are the ones who learn WHAT to do with them from the ones who know HOW!". They even integrated their new abilities into their role-play games: they built laptops and computers and added a mouse, performed an imaginary click and opened an imaginary file. Step-by-step they internalized the actions and the vocabulary.

\section{CONCLUSIONS AND FURTHER WORK}

This paper is a report of a challenging initiative to combine the process of developing edutainment applications with organizing ICT activities for the same users: preschool children aged 5 to 6 , as a step forward towards their future literacy. In the future we intend to extend this approach to identify an appropriate method to rigorously evaluate the effectiveness of using the edutainment applications in terms of learning outcomes in comparison to the classical teaching approach. There is also the intention to focus more on ICT activities organized for preschoolers in order to provide and support the development of a proper attitude towards technology and digital skills. And, an important aspect, we intend to collaborate with other experts in education, teachers, researchers, to enhance the methodological aspects and to validate the results.

\section{ACKNOWLEDGEMENTS}

We would like to thank all the children and their parents, kindergarten teachers and students who participated in this proposal. We would also like to thank for the given support to the kindergarten management team who fully supported this approach in nurturing the digital skills of preschoolers. 


\section{REFERENCES}

1. Bekker T., Markopoulos P. Interaction design and children. In:Interacting with Computers 15, 2003

2. Bloom, Benjamin, Taxonomy of Educational Objectives: The Classification of Educational Goals, Handbook I: Cognitive domain.. New York: David McKay Company, 1956

3. Chaudron, S., Di Gioia, R., Gemo, M., Young Children (0-8) and Digital Technology. A Qualitative study across Europe, European Commission, 2018

4. Curriculum pentru Educație timpurie, MEN, București, 2019,

https://www.edu.ro/sites/default/files/Curriculum\%20ET 2019 aug.pdf

5. Bogaert, C., Delmarle, S\&Preda, V., Formarea competențelor în grădiniță. O altă perspectivă asupra timpului şcolar. Ed. Aramis, Bucureşti, 2013

6.Creer, A. Introducing Everyday 'Digital Literacy Practices'into the Classroom: an Analysis of Multi-layered Media, Modes and their Affordances. Journal of New Approaches in Educational Research, 7(2), 131-139. doi: 10.7821/naer.2018.7.265, 2018

7.Crescenzi, L., Gran, M., An Analysis of the Interaction Design of the Best Educational Apps for Children Aged Zero to Eight. Comunicar, 46, 77-85.

8. Dulamă,E., Fundamente despre competențe, Teorie şi aplicații, Presa Universitară Clujeană, Cluj-Napoca, 2010

9. Dulamă, E., Despre competențe, Teorie şi practică, Presa Universitară Clujeană, Cluj-Napoca

10. Grasset, Raphaël, Dünser, Andreas, Billinghurst, Mark, Edutainment with a mixed reality book: a visually augmented illustrative childrens' book, ACE'08 Proceedings of the 2008 International Conference on Advances in Computer Entertainment Technology, Pages 292-295

11. Guran, A. M. Cojocar, G. S., and Dioşan L. S. 2020. A Step Towards Preschoolers' Satisfaction Assessment Support by Facial Expression Emotions Identification. In the 24th International Conference on Knowledge-Based and Intelligent Information \& Engineering Systems. to be published.

12. Guran, A. M. Cojocar, G. S. , and Moldovan, A. 2018. Initiative to Support Basic Digital Skills Development of Romanian Preschool Children. In 15th International Conference on Human Computer Interaction, RoCHI 2018, Cluj-Napoca, Romania, September 3-4, 2018, Adrian Sabou and Philippe A. Palanque (Eds.). Matrix Rom, 147-154.

13. Guran, A.M. Cojocar, G. S. and Moldovan A. M. 2019. Applying UCD for Designing Learning Experiences for Romanian Preschoolers. A Case Study. In Human-Computer Interaction - INTERACT 2019 - 17th IFIP TC 13 International Conference, Paphos, Cyprus, September 2-6, 2019, Proceedings, Part IV (Lecture Notes in Computer Science, Vol. 11749), David Lamas, Fernando Loizides, Lennart E. Nacke, Helen Petrie, Marco Winckler, and Panayiotis Zaphiris (Eds.). Springer, 589-594. https://doi.org/10.1007/978-3-030-29390-1_43

14. Guran, A.M. Cojocar, G. S. and Moldovan A. M. 2019. Co-Design of Edutainment Applications with Preschoolers. Is it feasible?. In 16th International Conference on Human-Computer Interaction, RoCHI 2019, Bucharest, Romania, October 17-18, 2019, Alin Moldoveanu and Alan J. Dix (Eds.). Matrix Rom, 92-97.

15. Guran, A.M. Cojocar, G. S. and Moldovan A. M. 2020. A User Centered Approach in Designing Computer Aided Assessment Applications for Preschoolers. In Proceedings of the 15th International Conference on Evaluation of Novel Approaches to Software Engineering, ENASE 2020, Prague, Czech Republic, May 5-6, 2020, Raian Ali, Hermann Kaindl, and Leszek A. Maciaszek (Eds.). SCITEPRESS, 506-513. https://doi.org/10.5220/00095655050605

16. Hourcade J. P. Interaction Design and Children Found. Trends Hum.-Comput. Interact. 1, 4 (April 2008), 277-392.

17. Markopoulos, P., Read, J., MacFarlane, S., Evaluating Children's Interactive Products. Principles and Practices for Interaction Designers, 2008

18. Piaget, Jean, Şase studii de Psihologie, 3 Publishing House, 2017

19. Raport OECD - UNICEF: Evaluările și examinările în sistemul de educație din România, https://www.edu.ro/raport-oecd-unicef-evalu $\% \mathrm{C} 4 \% 83$ rile -\%C $8 \% 99$ i-examin $\%$ C4\%83rile- $\%$ C3\%AEn-sistemul-deeduca $\% \mathrm{C} 8 \% 9 \mathrm{Bie}$-din-rom $\% \mathrm{C} 3 \% \mathrm{~A} 2$ nia, Iunie 2020

20. Rapeepisarn, Kowit, Wong, Kok Wai, Fung Chun Che, Depickere, Arnold, Similarities and differences between "learn through play" and "edutainment, https://pdfs.semanticscholar.org/f92a/aa7f6d54d2ca98b6f 64122f89d0beb6fdlee., Iunie 2019

21. Recommendation of the European Parliament and of the Council of 23 April 2008 on the establishment of the European Qualifications Framework for lifelong learning (Text with EEA relevance) $O J C$ 111, 6.5.2008, p. 1-7

22. Venn-Wycherley, Megan, Kharrufa, Ahmed, HOPE for Computing Education: Towards the Infrastructuring of Support for University-School Partnerships, CHI '19 Proceedings of the 2019 CHI Conference on Human Factors in Computing Systems, 2019 